\title{
Gamma knife surgery in management of secretory pituitary adenoma preliminary evaluation of role, efficacy and safety
}

\author{
Raef FA Hafez , Magad S. Morgan and Osama M. Fahmy \\ *Correspondence: raefhafez179@hotmail.com

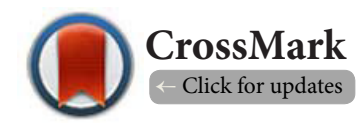

International Medical Center, Gamma Knife Center, Cairo, Egypt.

\begin{abstract}
Historically the treatment armamentarium for secretory pituitary adenomas included neurosurgery, medical management, fractionated radiotherapy and recently gamma knife surgery (GKS), the goal of this study is to evaluate the efficacy, safety and role of gamma knife surgery for treatment of secretory pituitary adenomas regarding hormonal and adenoma size control, between mid of 2005 and 2012 a retrospective analysis of 54 consecutive patients with secretory pituitary adenomas underwent GKS at the International Medical Center (IMC) Cairo-Egypt, 10 patients with adrenocorticotrophic hormone secreting adenoma, 24 prolactin secreting adenoma and 20 with growth hormone secreting adenoma, in 25 patients GKS was the secondary to a prior surgery with failure of hormonal control even in addition of medical treatment, in the other 29 the secretory pituitary adenomas not controlled with medical treatment alone, the median follow up period was 28 months(12-84 months), achieving hormonal control was either normalization or marked decline of abnormal hormone level $>50 \%$, radiological tumour size control was either tumour size stabilization or reduction, among the 54 patients 31 had microadenoma of 1cc volume or less, over all 34 patients (63\%) had hormonal control and 51 patients (94\%) had tumor size control after GKS, there was a direct correlation between tumor size, prescription radiation dose and post-gamma knife hormonal and size control, 29 out of the treated 31 microadenomas cases showed both hormonal and size control, inconclusions gamma knife surgery is safe and effective treatment for secretory pituitary adenomas failed to respond to medical treatment alone or with postsurgical residual or recurrence especially microadenomas.
\end{abstract}

Keywords: Acromegaly, cushing's disease, prolactinoma, radiosurgery

\section{Introduction}

Pituitary adenomas are common lesions and represent $20 \%$ of all primary brain tumors [1-3]. Pituitary adenomas are classified into two groups. The first is the secretory pituitary adenoma that produce excess of normal pituitary hormones usually they are microadenoma. Such functioning adenomas include those with Cushing's disease (high adernocorotitrophic hormone-ACTH, Acromegaly (high growth hormone-GH), Prolactinomaswith high prolactin hormone-PL, and rarely adenoma can overproduce more than one hormone. Occasionally some secretory microadenoma may produce pressure symptoms relating to compressing the optic pathway or invasion the cavernous sinus. The second are non-secretory pituitary adenomas that represent approximately $30 \%$ of pituitary adenomas, they are usually macoradenomas that enlarge and can extend beyond the confines of the sella turcica into the cavernous sinus, suprasellar region, infrasellar region, and even invade the clivus [4].

Surgery, fractionated radiotherapy and medication are the three key elements of the treatment strategy for secretory pituitary adenoma. Transsphenoidal microsurgery has remained the primary treatment for most patients with functioning adenomas causing acromegaly or Cushing's disease. Most prolactinomas can be controlled successfully by medical treatment and transsphenoidal microsurgery is the second treatment step [4].

The persistence or recurrence of secretory pituitary diseases due to tumour invasion into surrounding structures or incomplete tumour resection is quite common and long term tumour control rates after transsphenoidal excision alone vary from 50 to $80 \%$ [5]. For residual or recurrent tumours fractionated radiation therapy has been the traditional treatment. However, it has a prolonged latency for its effects and is associated with more frequent side effects as hypopituitarism and visual damage $[3,4,6]$.

In 1968, Leksell treated the first pituitary adenoma patient with the Gamma knife, since that time, stereotactic radiosurgery has become an important tool in the neurosurgical treatment for patients with pituitary adenomas [7]. Recently gamma knife surgery(GKS) has gained acceptance as primary minimally invasive treatment option for secreting pituitary micro adenomas or a complementary treatment option in combination with microsurgery for secreting macroadenomas. GKS can provide adenoma growth control and long-term endocrine control that is superior to that of repeat surgery and the long 
Hafez et al. Neuroscience Discovery 2014,

latency of the radiation response. Also GKS limits radiation exposure of the surrounding normal brain structures $[4,8]$.

\section{Materials and methods Patient population}

54 consecutive patients with secretory pituitary adenoma were treated with leksell GKS at the International Medical Centre Gamma Knife-Centre-Cairo-Egypt between mid of 2005 till mid of 2012, GKS was utilized in our study as an adjuvant treatment in all the studied 54 cases after being resistant to medical therapies or intolerant to its side effects, with or without previous pituitary surgiery. In 25 patients some form of prior surgery such as transsphenoidal resection, or craniotomy had been conducted with presence of residual especially that involve the cavernous sinus or recurrence. The median follow up periodwas 28 months(12-84 months). The others 29 patients has history of medical treatment failure without any surgical intervention, 21 of them has microadenomas of $10 \mathrm{~mm}$ maximum diameter or less, that usually referred directly by endocrinologist.

In all the treated cases optic apparatus was atleast 2-3mm distance from the treated adenoma. Radiological (MRI and sometimes CT scan); endocrinological, ophthalmological, and neuroradiological exams were conducted. The initial diagnosis was made on the basis of magnetic resonance imaging (MRI) findings, endocrinological exam, pathological findings (available for postoperative cases), and clinical history. In all patients, initial pre-GKS levels of ACTH, cortisol, and urinary free cortisol (UFC), GH and IGF-I, prolactin (PRL), $\mathrm{LH}, \mathrm{FSH}$, testosterone or estradiol, $\mathrm{TSH}$, and free $\mathrm{T}_{3}$ and $\mathrm{T}_{4}$ were obtained. Stopping of the antisecretory agent's 1 to 2 months before gamma knife surgery is advised in most of the treated patients.

The results were classified to Group I, where clinical improvement, tumor size control and hormonal control (hormonal normalization or marked decline $>50 \%$ compare to pregamma knife surgery) obtained without any post gamma knife antisecretory medical treatment, Group II where some hormonal decline $<50 \%$ with little improvement or stable clinical condition even with antisecretory drugs, Group III where there was a failure to achieve any hormonal control or decline with persistent clinical condition and sometime even worsen.

\section{Gamma knife procedure and neuroimaging}

Application of the stereotactic frame was performed under local anesthesia on the morning of the procedure. Stereotactic MRI then done to determine the pathology. The gamma knife procedure was done using, leksell gamma knife model B version from 2005 to mid of 2010 then leksell gamma knife model 4C-APS version till now. The stereotactic MRI sequences were performed on a 1.5 Tesla magnetic resonance machine. The stereotactic MRI sequences included T1 coronal cuts without contrast first then $\mathrm{T} 1$ coronal immediately after contrast injection then axial T1 and sagittal T1. MRI slices thickness is $1.5 \mathrm{~mm}$ thickness without any gap on zero angle. T2- coronal sequence may obtained especially in postsurgical cases to optimize visualization of optic apparatus, the Fat suppression techniques MRI sequence can prove useful for differentiating tumor from surgical fat grafts. CT is generally reserved for patients who cannot undergo an MRI (e.g., a patient with a pacemaker).

The stereotactic MRI sequences then transmitted to leksell gamma plan, where treatment plan done after which the treatment protocol pass to the leksell gamma knife control unit where treatment applied automatically with APS. Either the $4 \mathrm{~mm}$ or the $8 \mathrm{~mm}$ collimatorhelmet was utilized especially in microadenoma to achieve conformity and avoiding radiationneural injuries. In some cases plugging was applied to avoid optic structure, occasionally the 72 degree gamma angle of radiation beams was utilized so that the radiation beams were delivered parallel to the optic nerve avoiding intersection and injuries to optic apparatus. Nevertheless in many treated microadenomas 90 degree gamma angle fulfilled the same purpose.

\section{Follow up}

Follow up was conducted regularly each 6 months in the first year post GKS and then yearly, the median follow up period was 28 months (12-84 months). Follow up criteria including MRI with contrast, endocrinological, ophthalmological, assessment.

\section{Results}

This study is conducted on 54 patients with secretory pituitary adenoma treated with gamma knife surgery at the international medical center between the mid of 2005 and mid of 2012 with median follow up period of 28 months (12-84 months). There was 26 females and 28 males, age ranged between 17 years to 63 years (mean $=34.2 \mathrm{ys}$ ). In all the studied 54 there was failure to control high hormonal level, either postsurgical in 25 cases with residual or recurrences, and in 29 cases after failure of medical treatment alone or intolerance to drugs side effects without any previous surgery, 21 of these cases had adenoma of 1cc volume or less. The clinical characteristics of the treated patients are summarized in (Table 1); there were 20 patients with acromegaly (high GH), 10 patients with Cushing's disease (high ACTH and UFC) and 24 patients with prolactinoma (high PRL).

The peripheral prescription dose varied according to tumor size, type of hormonal secretion and proximity to optic apparatus, for acromegaly ranged $20-25 \mathrm{~Gy}$, in prolactinomas 18-22Gy and in Cushing's disease usually 25-30Gy. The isodose curve ranged between 35 to $60 \%$ with adenoma radiation coverage ranged between $93 \%$ to $100 \%$.

Optic apparatus in all cases received $<8 \mathrm{~Gy}, 3^{\text {rd }}$ cranial nerve in those with cavernous sinus invasion received $<21 \mathrm{~Gy}$ and pituitary gland and stalk received $<15 \mathrm{G} y$. The secretory pituitary adenoma volumes treated in this study ranged between 0.036 
Table 1. The clinical characteristics of the treated 54 patients with secretory pituitary adenoma.

\begin{tabular}{ll}
\hline \multicolumn{2}{c}{ Parameter value } \\
\hline $\begin{array}{l}\text { Total of patients with secretory pituitary } \\
\text { adenoma }\end{array}$ & 54 \\
Female & 26 \\
Male & 28 \\
Age (range) & $17-63 \mathrm{ys}$ (mean-34.2ys) \\
Follow-up (range) & $12-84$ months \\
Prior surgical intervention prior to GKS & 25 \\
$\begin{array}{l}\text { No Prior surgical intervention prior to } \\
\text { GKS }\end{array}$ & 29 \\
$\begin{array}{l}\text { Adenoma volume }>1 \mathrm{cc} \text { up to 3.7cc/ } \\
\text { macroadenoma }\end{array}$ & 23 \\
$\begin{array}{l}\text { Adenoma volume of } 1 \mathrm{cc} \text { or less/ } \\
\text { microadenoma }\end{array}$ & 31 \\
\hline
\end{tabular}

to 3.7 cubic centimeters (cc), their distribution were as follow: $3-3.84 \mathrm{cc}$ in 4 patients, $2 \mathrm{cc}-2.85 \mathrm{cc}$ in 11 patients, $1.2 \mathrm{cc}-1.98 \mathrm{cc}$ in 8 patients and $1 \mathrm{cc}$ volume or less in 31 patients.

The overall results of gamma knife surgery for the treated 54 patients (Table 2) were as follows: Group I, where 34 patients (63\%) had clinical improvement, tumor size control and hormonal control (hormonal normalization in 23 patients or marked decline $>50 \%$ in 11 patients compare to pre gamma knife surgery). Group II, where 12 patients (22\%) showed some hormonal decline $<50 \%$ with little improvement or stable clinical condition. Group III, where 8 cases (15\%) had failure to achieve any hormonal control with persistent clinical condition or even worsen. Hormonal control in our study did occurred within 12-36 months although clinical improvement sometimes happened before that.

Regarding adenoma sizes determined by MRI follow up post gamma knife surgery, 51 cases (94\%) out of the studied 54 cases showed tumor size control, in 41 of them the adenoma being stable size (local control), and in 10 cases the adenoma reduced in size, such reduction started usually after 12-24 months and sometimes continue.

Among the treated 24 prolactinoma patients, 15 patients (62\%) had hormonal control after at least two successive serum prolactin according to age and sex. Most of them responded after 12 months and up to 3 years, all treated with peripheral dose $20-22 \mathrm{~Gy}$ and 13 of them had adenoma size of $1 \mathrm{cc}$ volume or less, another 6 patients had hormonal decline $<50 \%$ and 3 the remaining patients showed failure of hormonal control they had adenoma volume of $2.6 \mathrm{cc}, 3.3 \mathrm{cc}$ and 3.4cc respectively, all of them treated with peripheral prescription dose limited to $18 \mathrm{~Gy}$ because of adenomas sizes and proximity to optic apparatus (Figures 1 and 2).

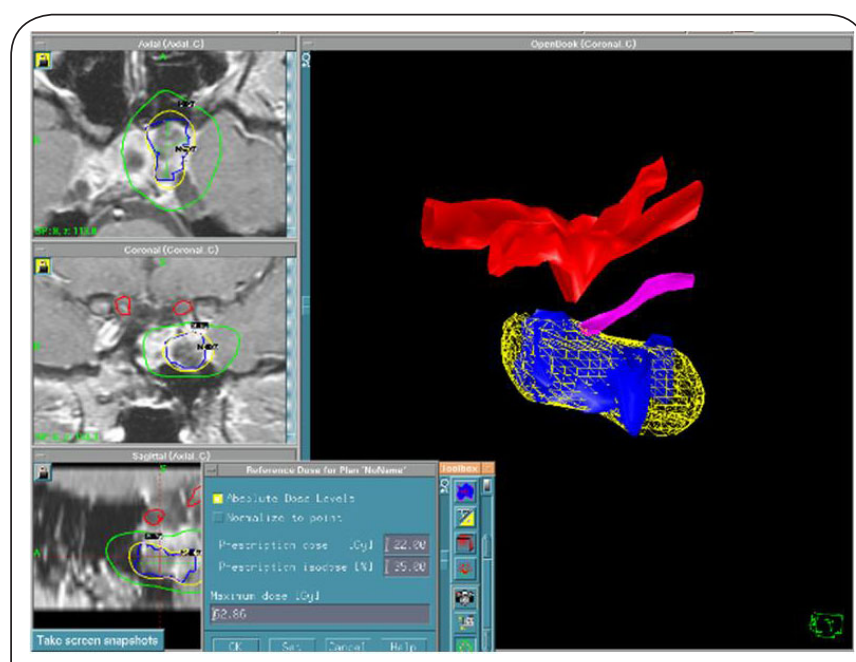

Figure 1. Gamma plan for postoperative postoperative residual prolactinoma, $1.9 \mathrm{cc}$ volume. The Prescription dose was $22 \mathrm{~Gy}$ to the $35 \%$ isodose curve.

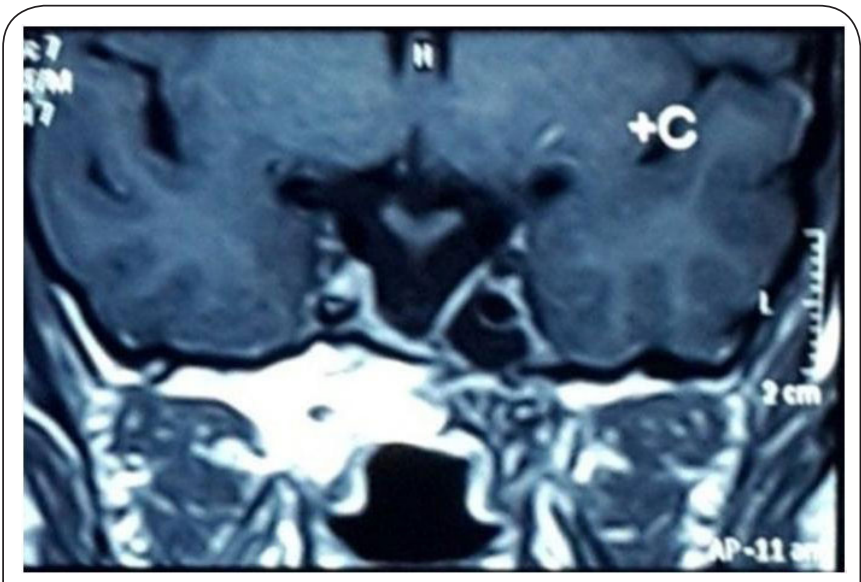

Figure 2. Follow up MRI for the same postoperative residual prolactinoma patients 4 years. Post-GKS with marked adenoma reduction.

Table 2. Hormonal and adenoma size control in the treated 54 patient with secretory pituitary adenoma.

\begin{tabular}{llllll}
\hline $\begin{array}{l}\text { Type of secretory } \\
\text { pituitary adenoma }\end{array}$ & $\begin{array}{l}\text { No of } \\
\text { patients }\end{array}$ & $\begin{array}{l}{ }^{\star} \text { Hormonal } \\
\text { control }\end{array}$ & $\begin{array}{l}\text { Hormonal } \\
\text { decline }<\mathbf{5 0} \%\end{array}$ & $\begin{array}{l}{ }^{\star} \text { Adenoma } \\
\text { growth control }\end{array}$ & $\begin{array}{l}\text { No of } \\
{ }^{\star} \text { Microadenoms }\end{array}$ \\
\hline Prolactinomas & 24 & $15(62 \%)$ & 6 & $23(96 \%)$ & 13 \\
Acromegaly & 20 & $12(60 \%)$ & 5 & $18(90 \%)$ & 11 \\
Cushing's disease & 10 & $7(70 \%)$ & 1 & $10(100 \%)$ & 7 \\
\hline
\end{tabular}

${ }^{\star}$ Hormonal control=hormonal normalization or marked decline $>50 \%$; ${ }^{\star}$ Adenoma growth control=decreased or stable in size; ${ }^{\star}$ Microadenoma $=10 \mathrm{~mm}$ maximum diameter or less 
Hafez et al. Neuroscience Discovery 2014,

In the treated 20 acromeyaglic patients 12 patients (60\%) had hormonal control(GH $<2,5 \mu \mathrm{g} / \mathrm{l})$ that usually happened after 12-24 months post GKS, 11 of them had adenoma volume of $1 \mathrm{cc}$ or less and all treated with marginal dose of 22-25Gy, 5 patients had hormonal decline $<50 \%$ and the remaining 3 patients had failure of hormonal control, their treated adenomas sizes were $2.6,2.8$ and $3.7 \mathrm{cc}$ respectively all these cases treated with peripheral dose of 22Gy or less because of tumor size and proximity to optic apparatus (Figures 3 and 4).

Among the treated 10 cases with Cushing's disease, 7 patients (70\%) had hormonal control with 24 -h free urinary cortisol in the normal range.

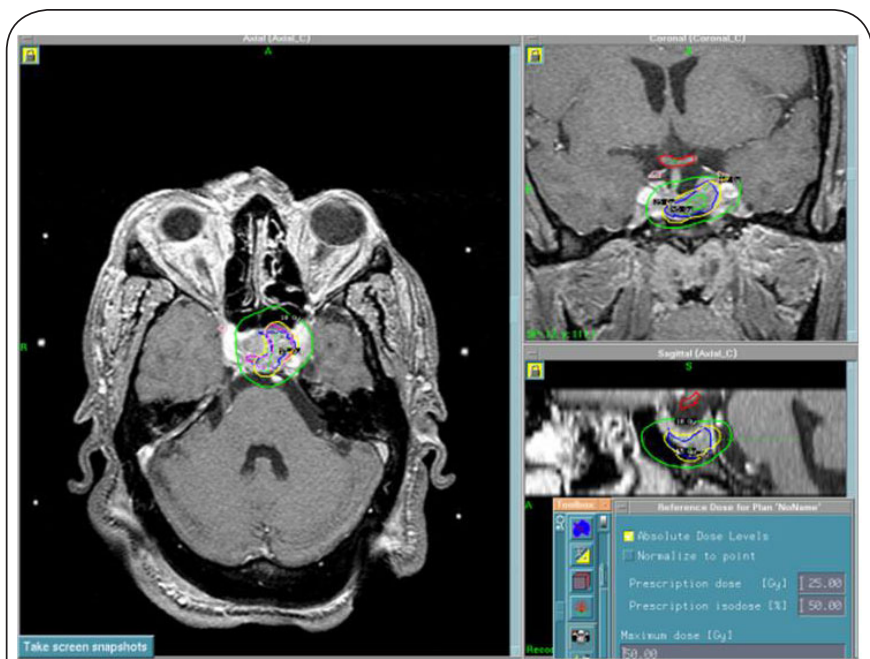

Figure 3. Gamma plan for Acromagelic patient with pituitary adenoma $1.8 \mathrm{cc}$ volume. The Prescription dose was 25Gy to 50 $\%$ isodose curve.

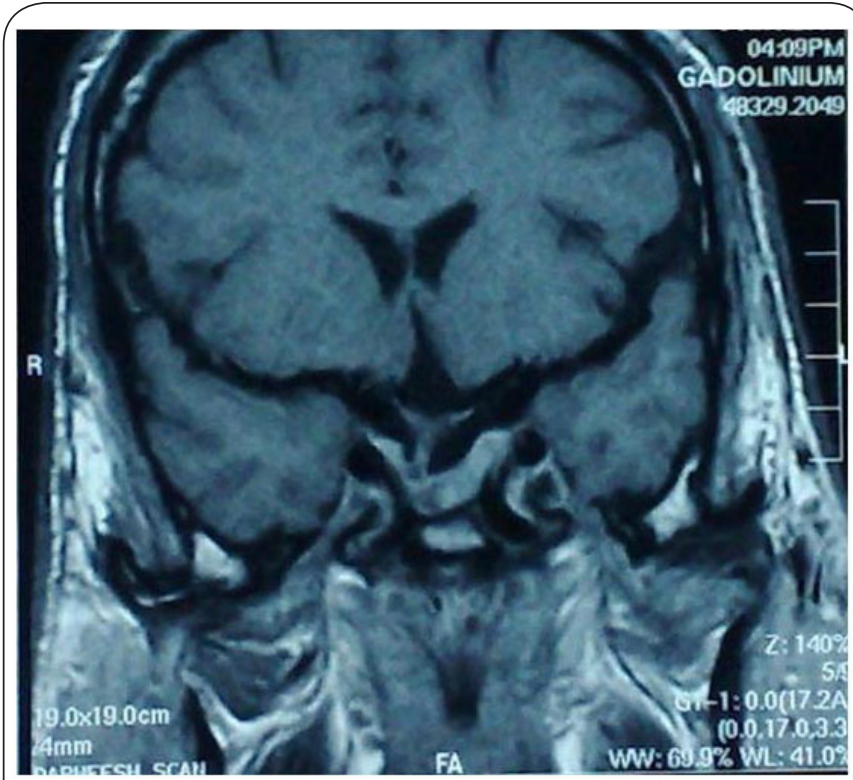

Figure 4. Follow up MRI for the same acromegalic patient 5 years post -GKS with Continue reduction of tumor size.
With peripheral prescription dose 25 to $30 \mathrm{~Gy}$ all of them had microadenoma of $1 \mathrm{cc}$ volume orless, one patient has hormonal decline $<50 \%$ with tumor size $2 \mathrm{cc}$ and in the remaining 2 cases there were failure of hormonal control their adenoma volume were 2,88 and $2.82 \mathrm{cc}$ and the prescription dose was $<25 \mathrm{~Gy}$ (Figures 5 and 6).

Overall among the 35 patient who showed hormonal control in our study there were 29 with microadenomas? Of $1 \mathrm{cc}$ volume or less. Taking into consideration that the whole number of treated micradenomas in our study was 31 cases.

\section{Complications}

One prolactinoma the treated patients developed $3^{\text {rd }}$ nerve

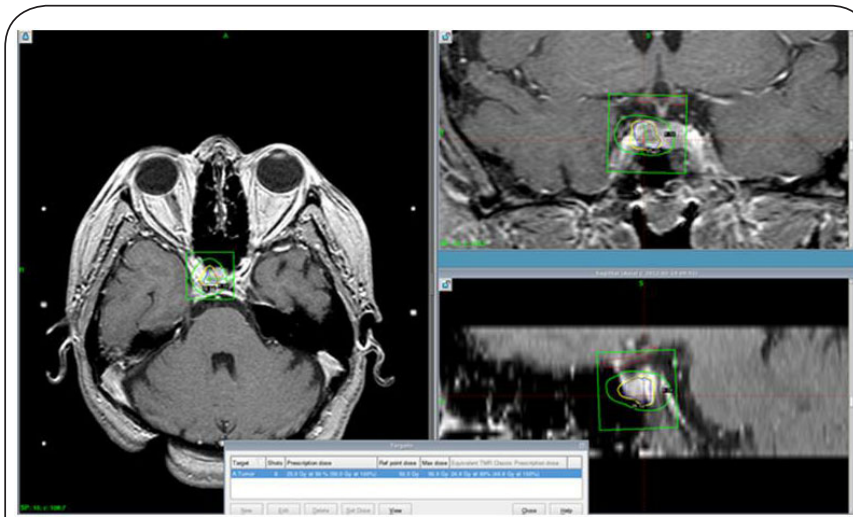

Figure 5. Gamma plan for Cushing's disease with pituitary microadenoma of $0.249 \mathrm{cc}$ volume. The prescription dose was $25 \mathrm{~Gy}$ to $50 \%$ isodose curve.

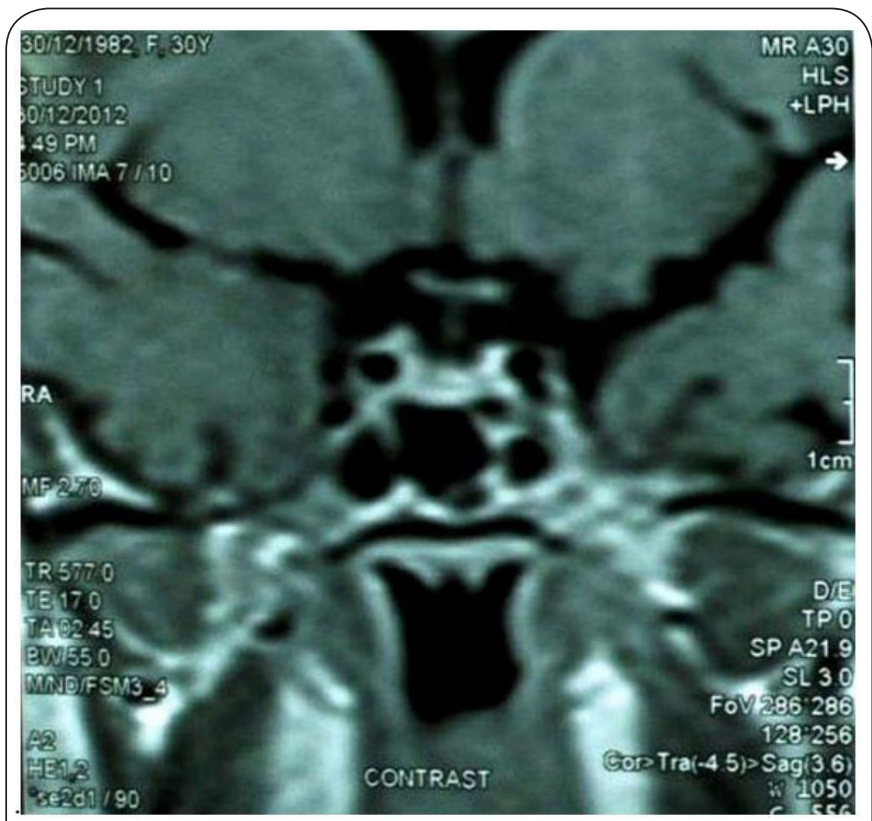

Figure 6. Follow up MRI for the same Cushing's disease with pituitary microadenoma 18 months follow up With tumor size reduction, being concave in coronal MRI sequence. 
palsy post-GKS, the patient had large prolactinoma residual with intracavernous sinus extension, he improved gradually with time.

Two patients in this study presented with one anterior pituitary hormone deficiency (gonadotrophic deficiency in one patient with Cushing's disease and thyrotrophic hormone deficiency in one prolactinoma patient), both detected after 36 months of follow up period, hormonal replacement was essential for these patients. None of our studied patients showed pan hypopituitarism picture through the follow up period. No additional visual complications occurred in all treated cases compare to pre-gamma knife surgery condition.

\section{Discussion}

There are multiple treatment modalities for secretory pituitary adenomas. Radiosurgery isan effective, noninvasive method for treating patients with functioning pituitary adenoma as a complement to the surgery. Pitutary adenoma that compresses the optic pathway should be removed with microsurgery and residual tumor especially in the cavernous sinus, recurrence and or resistant to medical treatment, is a good indication for radiosurgery [9]. In the treatment of pituitary adenomas, radiotherapy is classically indicated in cases of incomplete resection or recurrent tumors, functioning tumors uncontrolled by medical therapy and patients inoperable or who refuse surgery especially macroadenoma [10].

In our study, the goal of GKS, in treatment of secretory pituitary adenomas, is to control tumor growth andcontrol high hormonal secretion, GKS was utilized as an adjuvant treatment in all studied 54 cases after being resistant to medical therapies or intolerant to drugs side effects, with or without previous pituitary surgery. In 25 of them a prior pituitary surgery had been conducted with presence of residual or recurrence. The others 29 patients has history of medical treatment failure without pituitary surgery, 21 of these patients has functioning microadenomas of $10 \mathrm{~mm}$ maximum diameter or less who usually referred from endocrinologist directly.

Secretory adenomas require a higher radiation dose than non functioning pituitary adenomas [8]. Laws and Vance estimated that a higher percentage of control of hyper-functioning syndromes could be accomplished with the higher margin dose [2]. Ganz suggested that the effective dose for secretory adenomas should be higher than 25Gy [11].

The volumes of the secretory adenomas in our 54 studied patients were ranged between $3.7 \mathrm{cc}$ to $0.036 \mathrm{cc}, 31$ of them Had microadenomas. The peripheral prescription dose varied according to tumor size, type of hormonal secretion and proximity to optic apparatus, for acromegaly adenomas it was ranged 20-25Gy, in prolactinomas 18-22Gy and in Cushing's disease adenomas usually 25-30Gy. The isodose curve was ranged between $35 \%$ to $60 \%$ with adenoma coverage ranged between $93 \%$ to $100 \%$.

Hayashi et al., 1999, reported that the tumor growth control rate for pituitary adenoma after GKS was between
$93 \%$ to $94 \%$, and that the tumor shrinkage rate ranged from $46 \%$ to $56.7 \%$ [12]. Many studies reported a greater than $95 \%$ control of tumor size with follow-up varying from months to years [2,6]. Izawa et al., 2000, after mean follow up of 24 months in 79 secretory pituitary adenoma patients treated with GKS, reported local tumor control in $93.6 \%$ of patients, with reduction in $24.1 \%$, they prescribed a mean marginal dose of 22.5Gy [13].

Sheehan et al., in his extensive reviewed studies involving 1621 patients of secretory pituitary adenoma treated with radio surgery showed a mean tumor control rate of $96 \%$. Considering only the series with mean or median follow-up of 4 years or more $[4,10]$.

Regarding adenoma sizes determined by follow up MRI post-GKS in our study, 51 patients (94\%), showed tumor size control, 41 of them the adenomas being stable in size (local tumor control), and in 10 patients the adenoma reduced in size. The reduction in sizes happened usually after 18-24 months of follow up period.

Sheehan's et al., 2005, in his extensive reviewed studies reported the hormonal normalization ranged $17-83 \%$ in patients with Cushing's disease, $20-96 \%$ in patients with acromegaly and $0-84 \%$ in patients with prolactinoma [4].

Castro et al., 2010, in their study over 28 cases with functioning pituitary adenomas treated with radiosurgery found hormone control in $67 \%$ of patients with Cushing's disease, $40 \%$ of acromegalic patients and $44 \%$ of patients with prolactinoma [10].

Petrovich et al., 2003, reported a median time to normalization of hormonal after radiosurgery, 22, 18 and 24 months for patients with tumors that produce ACTH, GH and PRL, respectively [3]. Choi et al., reported a mean time to hormonal normalization of 21 months ranged 1 to 3 years [14].

Sheehan et al., 2011, in his study over 418 pituitary adenoma treated with GKS has found relation between marginal dose and endocrine remission. The tumor margin radiation dose was inversely correlated with time to endocrine remission. Smaller adenoma volume correlated with improved endocrine remission in those with secretory adenomas Concluded that smaller adenoma volume improves the probability of endocrine remission and lowers the risk of new pituitary hormone deficiency with GKS. A higher margin dose offers a greater chance of endocrine remission and control of tumor growth [15].

The overall results of gamma knife surgery for the treated 54 cases in this study were as follows: Group 1, where 34 patients (63\%) had clinical improvement, tumor size control and hormonal control (hormonal normalization in 23 patients and marked decline $>50 \%$ in 11 patients). Group II, where 12 patients (22\%) showed some hormonal decline $<50 \%$ with little improvement or stable clinical condition. Group III, where 8 patients (15\%) had failure to achieve any hormonal control.

Among the treated 24 prolactinoma patients in this work, 15 patients (62\%) had hormonal control most of them responded 
Hafez et al. Neuroscience Discovery 2014,

after 12 months and up to 3years, all treated with peripheral dose 20-22 Gy and 13 of them had microadenomas. In the treated 20 acromeyaglic patients, $12(60 \%)$ had hormonal control that usually happened after 12-24 months post GKS, in 11 of them the adenoma volume was1cc or less and they were treated with marginal dose of 22-25Gy. Among the treated 10 cases with Cushing's disease, 7 patients (70\%) had hormonal control with peripheral prescription dose 25 to $30 \mathrm{~Gy}$, all of them had adenoma volume of less than 1cc (microadenomas).

Overall among the 35 patients who achieved hormonal control in our study there were 29 patients with microadenomas of $1 \mathrm{cc}$ volume or less, taking into consideration that the whole number of treated micradenoma was 31 patients, this indicates that secretory pituitary adenoma volume has a great impact on results of gamma knife surgery in controlling the high abnormal hormonal level and controlling adenoma growth, giving chance to apply high prescription marginal and maximum dose and better radiation conformity without injuries of critical neural structures.

The incidence of hypopituitarism after radiosurgery reported in literature is quite variable. Older studies that included patients treated in the pre-computed tomography reported higher incidence [6].

Most studies suggest a maximum dose to optic apparatus of $8 \mathrm{~Gy}$ or less to keep the risk of optic neuropathy close to zero and a minimum 2-5 $\mathrm{mm}$ between the tumor and optical apparatus $[4,6]$. However, in patients with functioning adenomas where the dose increase may be related to an increase in hormonal control, some authors accept the maximum dose of $10 \mathrm{~Gy}$, since restricted to a small volume of the optical apparatus $[15,16]$.

In our studied 54 patientsoptic apparatus received $<8 \mathrm{~Gy}$, $3^{\text {rd }}$ cranial nerve in those with cavernous sinus invasion received $<21$ Gy and pituitary gland and stalk received $<15 \mathrm{~Gy}$. Two patients in this study developed oneanterior pituitary hormone deficiency (gonadotrophic deficiency in one patient with Cushing's disease and thyrotrophic hormone deficiency in one prolactinoma patient), both detected after 36 months of follow up period, hormonal replacement was essential for these patients. One prolactinoma patients developed $3^{\text {rd }}$ nerve palsy post-GKS, he had large prolactinoma residual with intracavernous sinus extension.

None of our cases showed pan hypopituitarism picture through the follow up period. No additional visual complications occurred in all treated cases compare to pre-gamma knife surgery visual status.

\section{Conclusions}

Although not usually an initial treatment for patients with secretory pituitary adenomas especially macroadenoma, gamma knife surgery is safe and highly effective treatment for secretory pituitary adenoma patients who showed failure to achieve hormonal control after medical treatment alone, intolerant to its side effects, or post operative with residual functioning adenoma or recurrence. GKS is safe and an effective method for controlling secretory pituitary adenoma growth and inducing hormonal control especially in microadenoma with low morbidity and could be a primary minimal invasive option. The hormonal and tumor growth control in treatment secretory pituitary adenoma with GKS are correlated to adenoma size and prescription radiation dose, smaller pituitary permits high marginal dose giving high chance for rapid hormonal and growth control and low risk for pituitary function disturbance or visual apparatus injuries.

\section{List of abbreviations}

ACTH: adrenocorticotrophic hormone

$\mathrm{GH}$ : growth hormone

IGF-I: insulin-like growth factor I

GKS: gamma knife surgery

PRL: prolactin

UFC: urinary free cortisol

\section{Competing interests}

The authors declare that they have no competing interests.

Authors' contributions

\begin{tabular}{|l|c|c|c|}
\hline Authors' contributions & RFH & MSM & OMF \\
\hline Research concept and design & $\checkmark$ & $\checkmark$ & $\checkmark$ \\
\hline Collection and/or assembly of data & $\checkmark$ & -- & -- \\
\hline Data analysis and interpretation & $\checkmark$ & -- & -- \\
\hline Writing the article & $\checkmark$ & -- & -- \\
\hline Critical revision of the article & $\checkmark$ & -- & -- \\
\hline Final approval of article & $\checkmark$ & $\checkmark$ & $\checkmark$ \\
\hline
\end{tabular}

Acknowledgement

The authors wish to express many thanks to Dr. Tiit Rahn Department of Neurosurgery and gamma knife center Karolinska University Hospital S-171 76 Stockholm, Sweden for his help and for valuable suggestions and discussion.

\section{Publication history}

EIC: Tadanori Tomita, Northwestern University Feinberg School of Medicine, USA.

Received: 24-Apr-2014 Final Revised: 23-May-2014

Accepted: 29-May-2014 Published: 09-Jun-2014

\section{References}

1. Landolt AM and Lomax N. Gamma knife radiosurgery for prolactinomas. J Neurosurg. 2000; 93 Suppl 3:14-8. | Article | PubMed

2. Laws ER, Jr. and Vance ML. Radiosurgery for pituitary tumors and craniopharyngiomas. Neurosurg Clin N Am. 1999; 10:327-36. | Article | PubMed

3. Petrovich Z, Jozsef G, Yu C and Apuzzo ML. Radiotherapy and stereotactic radiosurgery for pituitary tumors. Neurosurg Clin N Am. 2003; 14:14766. I Article I PubMed

4. Sheehan JP, Niranjan A, Sheehan JM, Jane JA, Jr., Laws ER, Kondziolka $D$, Flickinger J, Landolt AM, Loeffler JS and Lunsford LD. Stereotactic radiosurgery for pituitary adenomas: an intermediate review of its safety, efficacy, and role in the neurosurgical treatment armamentarium. J Neurosurg. 2005; 102:678-91. | Article I PubMed

5. Friedman RB, Oldfield EH, Nieman LK, Chrousos GP, Doppman JL, Cutler GB, Jr. and Loriaux DL. Repeat transsphenoidal surgery for Cushing's 
Hafez et al. Neuroscience Discovery 2014 ,

disease. J Neurosurg. 1989; 71:520-7. | Article | PubMed

6. Thoren M, Hoybye C, Grenback E, Degerblad M, Rahn T and Hulting AL. The role of gamma knife radiosurgery in the management of pituitary adenomas. J Neurooncol. 2001; 54:197-203. | Article | PubMed

7. Landolt AM, Haller D, Lomax N, Scheib S, Schubiger O, Siegfried J and Wellis $\mathrm{G}$. Stereotactic radiosurgery for recurrent surgically treated acromegaly: comparison with fractionated radiotherapy. J Neurosurg. 1998; 88:1002-8. | Article | PubMed

8. Niranjan $A$ and Lunsford LD. Radiosurgery: where we were, are, and may be in the third millennium. Neurosurgery. 2000; 46:531-43. | Article | PubMed

9. Landolt AM, Haller D, Lomax N, Scheib S, Schubiger O, Siegfried J and Wellis $\mathrm{G}$. Stereotactic radiosurgery for recurrent surgically treated acromegaly: comparison with fractionated radiotherapy. J Neurosurg. 1998; 88:1002-8. | Article | PubMed

10. Wan $\mathrm{H}$, Chihiro $\mathrm{O}$ and Yuan S. MASEP gamma knife radiosurgery for secretory pituitary adenomas: experience in 347 consecutive cases. $J$ Exp Clin Cancer Res. 2009; 28:36. | Article | PubMed Abstract | PubMed Full Text

11. Castro DG, Cecilio SA and Canteras MM. Radiosurgery for pituitary adenomas: evaluation of its efficacy and safety. Radiat Oncol. 2010; 5:109. | Article | PubMed Abstract | PubMed Full Text

12. Ganz JC. Gamma Knife Applications in and around the Pituitary Fossa Gamma Knife Surgery A Guide for Referring Physicians. Springer. 1993; 122-132. | Article

13. Hayashi M, Izawa M, Hiyama H, Nakamura S, Atsuchi S, Sato H, Nakaya K, Sasaki K, Ochiai T, Kubo O, Hori T and Takakura K. Gamma Knife radiosurgery for pituitary adenomas. Stereotact Funct Neurosurg. 1999; 72 Suppl 1:111-8. | Article | PubMed

14. Izawa M, Hayashi M, Nakaya K, Satoh H, Ochiai T, Hori T and Takakura K. Gamma knife radiosurgery for pituitary adenomas. J Neurosurg. 2000; 93 Suppl 3:19-22. | Article | PubMed

15. Choi JY, Chang JH, Chang JW, Ha Y, Park YG and Chung SS. Radiological and hormonal responses of functioning pituitary adenomas after gamma knife radiosurgery. Yonsei Med J. 2003; 44:602-7. | Article | PubMed

16. Sheehan JP, Pouratian N, Steiner L, Laws ER and Vance ML. Gamma Knife surgery for pituitary adenomas: factors related to radiological and endocrine outcomes. J Neurosurg. 2011; 114:303-9. | Article | PubMed

17. Pollock BE, Nippoldt TB, Stafford SL, Foote RL and Abboud CF. Results of stereotactic radiosurgery in patients with hormone-producing pituitary adenomas: factors associated with endocrine normalization. $J$ Neurosurg. 2002; 97:525-30. | Article | PubMed

\section{Citation:}

Hafez RFA, Morgan MS and Fahmy OM. Gamma knife surgery in management of secretory pituitary adenoma preliminary evaluation of role, efficacy and safety. Neurosci Discov. 2014; 2:4.

http://dx.doi.org/10.7243/2052-6946-2-4 